Sharif University of Technology
Scientia Iranica
Transactions E: Industrial Engineering
hCIENTIA

\title{
DEA altruism and exclusiveness cross-efficiency evaluation models
}

\author{
L. Li ${ }^{\mathrm{a}}, \mathrm{W} \cdot \mathrm{Dai}^{\mathrm{b}}, \mathrm{J} \cdot \mathrm{Chu}^{\mathrm{c}, *}, \mathrm{X} \cdot \mathrm{Liu}^{\mathrm{d}}$, and Y. Wang ${ }^{\mathrm{e}}$ \\ a. School of Business, Applied Technology College of Soochow University, Suzhou 215325, PR China. \\ b. Research Center for Smarter Supply Chain, Soochow Think Tank \& Dongwu Business School, Soochow University, Suzhou \\ 215012, PR China. \\ c. School of Business, Central South University, 410083 Hunan, PR China. \\ d. School of Management, University of Science and Technology of China, Hefei 230026, PR China. \\ e. School of Business, Jiangnan University, Wuxi, 214122, PR China.
}

Received 10 July 2017; received in revised form 18 August 2018; accepted 29 April 2019

\section{KEYWORDS \\ Data Envelopment Analysis (DEA); Cross-efficiency evaluation; Altruism model; Exclusiveness model; Efficiency.}

\begin{abstract}
As an effective method for evaluating efficiency, cross-efficiency evaluation has been widely used to assess the performance of Decision-Making Units (DMUs). However, non-uniqueness of the optimal weights problem reduces efficiency of this method. To address this problem, scholars have proposed using secondary goals and they have developed numerous models with this consideration. In this paper, two new secondary goal models are presented in order to further extend the above-mentioned existing models. The proposed altruism cross-efficiency model is specifically applicable when the evaluated DMU cooperates with other DMUs, since it maximizes the peer-efficiency scores of other DMUs. On the other hand, the exclusiveness cross-efficiency model is utilized when the evaluated DMU is competing with other DMUs. This model minimizes the peer-efficiency scores of other DMUs. Compared with the existing approaches, our approach ensures that the peerefficiencies generated by each DMU are maximized (or minimized) under the premise that the minimum (or maximum) peer-efficiency among the DMUs is maximized (or minimized). More importantly, our proposed algorithm guarantees the uniqueness of the optimal weights and the set of cross-efficiency scores. Two numerical examples were used to verify the effectiveness of the proposed model.
\end{abstract}

(C) 2020 Sharif University of Technology. All rights reserved.

\section{Introduction}

As an effective method for efficiency evaluations, Data Envelopment Analysis (DEA) has been widely used to assess the performance and relative efficiency of Decision-Making Units (DMUs). The method was first introduced by Charnes et al. [1], who proposed the original DEA model (CCR model). Since then, it

*. Corresponding author. Tel.: +86 15656572793 E-mail addresses: cjf0731@mail.ustc.edu.cn (J. Chu); wyh2003@gmail.com (Y. Wang)

doi: $10.24200 /$ sci. 2020.21994 has been further extended by numerous scholars and researchers. Compared to other methods, DEA has many obvious advantages. On the one hand, DEA can be used to evaluate the efficiency of DMUs that have multiple inputs and multiple outputs [2]. On the other hand, providing any subjective information for decision makers before evaluation is unnecessary when DEA is used [3]. Therefore, DEA results are highly objective and unbiased. On the other hand, the traditional DEA models also have a number of disadvantages. For example, they are evaluated from the perspective of self-evaluation. In addition, the evaluated DMUs select their most preferable weights in order to maximize their own efficiency scores. Therefore, more than one 
DMU will be evaluated as DEA-efficient and the DEAefficient DMUs cannot be further discriminated by the DEA CCR model [4].

To overcome the shortcomings mentioned above, Sexton et al. [5] proposed the cross-efficiency evaluation method, which is discussed in Section 2. The central idea of the method is to obtain the peerefficiency scores of other DMUs by using the optimal weights of the evaluated DMU. Then, the average of $\mathrm{n}$ efficiency scores (including $n-1$ peer-efficiency scores and one self-efficiency score) is used as the final efficiency evaluation index. This method brings at least three benefits. Firstly, a unique ranking order of all DMUs can be obtained through the above method [5]. Secondly, this method can decrease the emergence of unrealistic weights [6]. Finally, the cross-efficiency evaluation method can distinguish be- tween good performers and bad performers [7]. Thus far, the method has been widely applied in a variety of areas and studies [5,8-13].

However, some defects still exist in the crossefficiency evaluation method. For example, because of the non-unique optimal weights calculated by the CCR model, the peer-efficiency scores of other DMUs may also be non-unique. To address this problem, we propose the use of DEA models with secondary goals. Among all secondary-goal models, the benevolent and aggressive models proposed by Sexton et al. [5] and Doyle and Green [14] are the most classical. These models will also be introduced in Section 2. To date, on the basis of the traditional benevolent and aggressive models, many scholars and researchers have presented a significant number of new benevolent and aggressive models, which can be utilized in different application scenarios. For instance, Liang et al. [15] proposed three models with different secondary goals (including minimum total deviation). Due to their unrealistic target efficiencies, the models presented by Liang et al. [15] were further extended by Wang et al. [16], whose models changed the target efficiency of each DMU from 1 to its CCR efficiency. In addition, Lim [17] proposed two DEA models with new secondary goals in order to maximize (or minimize) the peer-efficiency score of the DMU with the worst (or best) performance. Subsequently, $\mathrm{Wu}$ et al. [18] pointed out that the target efficiency (CCR efficiency) in the Wang et al. [19] models was still unreachable for DMUs. Therefore, they presented a new method to obtain the maximum and minimum peer-efficiency scores of every DMU. They proposed other secondary goal models that could be used to calculate the peer-efficiency scores of DMUs, taking into consideration the willingness of DMUs to be close to their maximum and as far as possible from their minimum peer-efficiency scores.

In addition, Wang et al. [16] pointed out that an evaluated DMU should ignore the influence of other
DMUs. The evaluated DMU should select its own most favorable weights. Therefore, they proposed a neutral DEA model, which could effectively avoid the appearance of zero output weights. However, because Wang and Chins model only considered the constraints of output weights, a new neutral DEA model was presented for cross-efficiency evaluation, which could avoid the simultaneous emergence of zero weights of outputs and inputs. Moreover, by incorporating an ideal DMU and an anti-ideal DMU into the neutral DEA model, Wang et al. [16] provided a new perspective on the study of neutral DEA models. They proposed a neutral DEA model in which the distance between the evaluated DMU and the ideal DMU as well as the distance between the evaluated DMU and the anti-ideal DMU was taken into account. In addition, other neutral DEA models have been proposed that can be employed in reducing the difference in weighted inputs and outputs. For instance, a weight-balanced DEA model was proposed by $\mathrm{Wu}$ et al. [20] to reduce the difference in weighted inputs and weighted outputs. In their model, each weighted input (and weighted output) was considered as an independent individual. In order to reduce the number of zero weights, Sun et al. [21] presented a weight-optimized DEA model that could reduce differences between weighted inputs and outputs.

Apart from the models mentioned above, there are also other DEA models based on different perspectives. For example, $\mathrm{Wu}$ et al. [22] maintained that DMUs should be more concerned about their ranking order than about their efficiency scores in some cases such as the selection of projects and preference voting. Accordingly, they proposed a rank priority model as a means of optimizing the ranking order of DMUs. In addition, Wu et al. [18] mentioned a traditionally unnoticed shortcoming of cross-efficiency evaluation, that is, the obtained cross-efficiency scores might not be Pareto optimal. Therefore, many DMUs are unwilling to accept average cross-efficiency score as the final efficiency evaluation measure. To address this problem, they proposed a cross-efficiency evaluation method based on Pareto improvement. Song and Liu [23] pointed out that the traditional average crossefficiency evaluation method failed to reflect the real performance of all DMUs. They presented a variation coefficient method as a means for aggregating the crossefficiency scores. In addition, Ruiz and Sirvent [24] proposed a fuzzy approach as a technique to rank DMUs with imprecise data. To measure the efficiency scores of DMUs, Chen [25] presented an approach on the basis of lexicographical evaluation of DMUs. Chens approach could effectively avoid overestimating the efficiency scores of DMUs. In order to consider the attitude of decision makers on risk preference, Liu et al. [26] proposed a prospect cross-efficiency 
approach based on prospect theory. They concluded that other models were special cases of the prospect cross-efficiency approach. Kao and Liu [27] integrated cross-evaluation method into the two-stage DEA for assessing the cross efficiencies of two basic network systems. They concluded that the proposed method not only improved the discriminating ability of the network system ranking, but also identified the relationship between system and departmental efficiency.

In many practical applications, competition exists between DMUs. The traditional cross-efficiency evaluation method faces difficulty in dealing with this kind of situation. To solve the competition issue, scholars focused on the study of the game cross-efficiency model. In the study of Liang et al. [28], every DMU was deemed to be a player in a non-cooperative game. Each DMU was given a corresponding algorithm, which was proven to be convergent to the game cross-efficiency score. On the basis of the DEA game cross-efficiency model, Wu et al. [22] proposed a new method of ranking the candidates of a preferential election. In addition, by extending the model of Liang et al. [28], Wu et al. [29] presented a modified DEA game crossefficiency model. Wu used the model to evaluate the performances of different countries in the 2004 Olympic Games. Roboredo et al. [13] used the DEA game crossefficiency model to calculate the efficiency scores of Brazilian football teams. In Roboredos model, each team was considered a DMU. Based on the algorithm developed by Liang et al. [28], Sun et al. [30] proposed a DEA non-cooperation game model to allocate the emission permits. Wu et al. [18] introduced the concept of satisfaction degree into cross-efficiency evaluation approach. Then, the proposed method was adopted to evaluate the information technology in order to select the best option for the considered enterprise. Liu et al. [31] presented an equitable cross-efficiency model by integrating undesirable outputs. Then, the proposed method was used to analyze the ecological efficiency of coal-fired power plants. Chen et al. [32] used a game cross efficiency model to assess and analyze the China's provincial power efficiency. By analyzing the efficiency result from temporal and spatial perspectives, they suggested differential energy policies for China's provinces.
From the above literature review, one can conclude that the research into cross-efficiency evaluation has made great progress in recent years. However, most of the existing secondary goal models mainly focus on maximizing (or minimizing) the average peerefficiency scores of all DMUs, thus failing to maximize (or minimize) the peer-efficiency level for each single case. In addition, most of these models still cannot guarantee the uniqueness of optimal weights. In order to solve the mentioned problems and further extend the existing secondary goal models, this paper proposes two different models, namely the altruism and exclusiveness cross-efficiency models, based on different application scenarios. When the evaluated DMU is cooperative with other DMUs, the secondary altruism goal of the evaluated DMUs is to maximize the peerefficiency score of each of the other DMUs. When the evaluated DMU is competing with the other DMUs, the secondary exclusiveness goal is to minimize the peer-efficiency score of each of the other DMUs. To linearly solve the proposed models, the corresponding algorithms are also presented.

The rest of the present paper is organized as follows. The CCR model, classical cross-efficiency evaluation method, and traditional benevolent and aggressive models are briefly introduced in Section 2 . An altruism cross-efficiency and an exclusiveness crossefficiency model with the corresponding algorithms are presented in Section 3. Two illustrative examples are given in Section 4. Finally, Section 5 gives the concluding remarks.

\section{CCR model and Data Envelopment Analysis (DEA) cross-efficiency evaluation}

\subsection{Notation summary}

To facilitate model formulation, the notation used in this study is summarized in Table 1.

\subsection{CCR model and cross-efficiency evaluation}

Assume that there are $n$ DMUs to be evaluated. Each DMU consumes $m$ inputs to produce $s$ outputs. For $\mathrm{DMU}_{j}(j=1,2, \ldots, n)$, the $i$ th input is denoted by $x_{i j}$

Table 1. Notations.

\begin{tabular}{ll}
\hline Notations & \multicolumn{1}{c}{ Explanation } \\
\hline$x_{i j}$ & $i$ th input consumed by $\mathrm{DMU}_{j}$ \\
$y_{r j}$ & $r$ th output produced by $\mathrm{DMU}_{j}$ \\
$\omega_{i d}$ & Weight of the $i^{t h}$ input of $\mathrm{DMU}_{d}$ \\
$\mu_{r d}$ & Weight of the $r^{t h}$ output of $\mathrm{DMU}_{d}$ \\
$E_{d d}$ & $\mathrm{DMU}_{d}$ 's self-evaluated efficiency \\
$E_{j}$ & $\mathrm{DMU}_{j}$ 's cross-efficiency score \\
$E_{d j}$ & Peer-efficiency score of $\mathrm{DMU}_{j}$ evaluated by $\mathrm{DMU}_{d}$ \\
$e_{j}$ & Maximum peer-efficiency score of $\mathrm{DMU}_{j}$ evaluated by $\mathrm{DMU}_{d}$ \\
\hline
\end{tabular}


and the $r$ th output is denoted by $y_{r j}$. The self-efficiency score of the evaluated DMU, which is denoted by $E_{d d}$, can be obtained by the following linear programming model (1). This model was originally proposed by Charnes et al. [1] abbreviated to CCR model.

$$
\max \quad E_{d d}=\sum_{r=1}^{s} u_{r d} y_{r d}
$$

s.t.:

$\sum_{r=1}^{s} u_{r d} y_{r j}-\sum_{i=1}^{m} w_{i d} x_{i j} \leq 0, \quad \forall j$

$\sum_{i=1}^{m} w_{i d} x_{i d}=1$,

$u_{r d}, w_{i d} \geq 0, \quad \forall i, r$.

In Model (1), $w_{i d}(i=1,2, \ldots, m)$ and $u_{r d}(r=$ $1,2, \ldots, s)$ are the weights of the $i$ th input and the $r$ th output of $\mathrm{DMU}_{d}$, respectively. A set of optimal weights $\left(w_{i d}^{*}, u_{r d}^{*}, \forall j\right)$ and the optimal self-efficiency score $E_{d d}$ can be obtained by solving Model (1). If $E_{d d}=1$, then $\mathrm{DMU}_{d}$ is called DEA-efficient; otherwise, it is DEA-inefficient. Utilizing the optimal weights of DMUd, the peer-efficiency scores of $\mathrm{DMU}_{j}(j=$ $1,2, \ldots, n)$ evaluated by $\mathrm{DMU}_{d}$ could be calculated by the following formula:

$$
E_{d j}=\frac{\sum_{r=1}^{s} u_{r d}^{*} y_{r j}}{\sum_{i=1}^{m} w_{i d}^{*} x_{i j}}, \quad \forall j .
$$

For $\mathrm{DMU}_{j}(j=1,2, \ldots, n)$, the average of all its efficiency scores, denoted by $E_{j}$, can be calculated by Eq. (3) for the final efficiency evaluation measure:

$$
E_{j}=\frac{1}{n} \sum_{d=1}^{n} E_{d j}, \quad \forall j .
$$

The non-uniqueness of optimal weights in Model (1) will most likely lead to different crossefficiency scores in Eq. (2). To address this problem, secondary goals are incorporated into the crossefficiency evaluation method. Of all the secondary goal models, the most commonly utilized are the traditional benevolent and aggressive models proposed by Sexton et al. [5] and Doyle and Green [14], which are shown below as Model (4) and Model (5), respectively.

$$
\max \sum_{r=1}^{s} u_{r d}\left(\sum_{j=1, j \neq d}^{n} y_{r j}\right)
$$

s.t.

$$
\sum_{r=1}^{s} u_{r d} y_{r j}-\sum_{i=1}^{m} w_{i d} x_{i j} \leq 0, \quad \forall j
$$

$$
\begin{aligned}
& E_{d d} \cdot \sum_{i=1}^{m} w_{i d} x_{i d}-\sum_{r=1}^{s} u_{r d} y_{r d}=0 \\
& \sum_{i=1}^{m} w_{i d}\left(\sum_{j=1, j \neq d}^{n} x_{i j}\right)=1, \\
& u_{r d}, w_{i d} \geq 0 \quad \forall i, r . \\
& \min \sum_{r=1}^{s} u_{r d}\left(\sum_{j=1, j \neq d}^{n} y_{r j}\right) \\
& \text { s.t. } \\
& \sum_{r=1}^{s} u_{r d} y_{r j}-\sum_{i=1}^{m} w_{i d} x_{i j} \leq 0, \quad \forall j \\
& E_{d d} \cdot \sum_{i=1}^{m} w_{i d} x_{i d}-\sum_{r=1}^{s} u_{r d} y_{r d}=0 \\
& \sum_{i=1}^{m} w_{i d}\left(\sum_{j=1, j \neq d}^{n} x_{i j}\right)=1, \\
& u_{r d}, w_{i d} \geq 0 \quad \forall i, r .
\end{aligned}
$$

The core idea of the traditional benevolent (aggressive) model is to identify a set of the optimal weighs of $\mathrm{DMU}_{d}$. This model can thus maximize (or minimize) the average peer-efficiency scores of other DMUs as much as possible, while retaining the optimal self-efficiency score for each DMU. Although these two models can reduce the non-uniqueness of optimal weights to a certain extent, each of them still has some drawbacks. For example, only maximizing or minimizing the average peer-efficiency scores of other DMUs is likely to lead to the emergence of extreme results. Specifically, some cross-efficiency scores may be very large, while others are very small, as seen in Models (4) and (5).

\section{The altruism and exclusiveness cross-efficiency models}

This section presents two improved cross-efficiency models, namely altruism and exclusiveness models. The altruism model first identifies the DMU (called DMU1) with the minimal peer-efficiency, and then maximize the peer-efficiency of DMU1. Afterwards, it continues to identify the DMU (called DMU2) with the minimal peer-efficiency from the remaining DMUs and maximizes the peer-efficiency of DMU2. This step is repeated until peer-efficiencies of all DMUs are obtained. However, the exclusiveness model obtains the peer-efficiencies of DMUs from an opposite angle. 
It first identifies the DMU with the maximal peerefficiency (called DMU1) and then, minimizes its peerefficiency. Then, the exclusiveness model continues to identify the DMU with the maximal peer-efficiency from the remaining DMUs (called DMU2) and minimizes its peer-efficiency. This step is repeated until peer-efficiencies of all DMUs are obtained.

\subsection{The altruism cross-efficiency model}

If the evaluated DMU is cooperative with other DMUs, not only should the evaluated weights of DMUs ensure the optimal self-efficiency score, but also the peerefficiency scores of other DMUs will be maximized. We present the altruism cross-efficiency model (6) to deal with this situation.

$$
\max _{w, u} \min _{1 \leq j \leq n, j \neq d} E_{d j}=\frac{\sum_{r=1}^{s} u_{r d} y_{r j}}{\sum_{i=1}^{m} w_{i d} x_{i j}}
$$

s.t.

$$
\begin{aligned}
& \sum_{r=1}^{s} u_{r d} y_{r j}-\sum_{i=1}^{m} w_{i d} x_{i j} \leq 0, \quad \forall j \\
& \sum_{r=1}^{s} u_{r d} y_{r d}=E_{d d} \\
& \sum_{i=1}^{m} w_{i d} x_{i d}=1 \\
& u_{r d}, w_{i d} \geq 0 \quad \forall i, r .
\end{aligned}
$$

The maximum peer-efficiency score of $\mathrm{DMU}_{j}(j=$ $1,2, \ldots, n)$ as evaluated by $\mathrm{DMU}_{d}$ can be obtained through Model (6) while $\mathrm{DMU}_{d}$ is retained as the optimal self-efficiency score $\left(E_{d d}\right)$. In fact, Model (6) is a multi-objective linear programming model. The first objective of Model (6) is to identify the DMU with the highest minimal peer-efficiency score among all DMUs. The second objective is to maximize the minimal peerefficiency score through the weights of $\mathrm{DMU}_{d}$.

The corresponding steps are designed to find the final solution for Model (6):

Step 1: Let $l=1$; then, convert Model (6) into Model (7).

$$
\begin{aligned}
& \max _{w, u} \beta \\
& \text { s.t. } \\
& \sum_{r=1}^{s} u_{r d} y_{r j}-\sum_{i=1}^{m} w_{i d} x_{i j} \leq 0, \quad \forall j, \\
& \sum_{r=1}^{s} u_{r d} y_{r d}=E_{d d},
\end{aligned}
$$

$$
\begin{aligned}
& \sum_{i=1}^{m} w_{i d} x_{i d}=1, \\
& \sum_{r=1}^{s} u_{r d} y_{r j}-\beta \cdot \sum_{i=1}^{m} w_{i d} x_{i j} \leq 0, \quad \forall j, j \neq d, \\
& u_{r d}, w_{i d} \geq 0 \quad \forall i, r .
\end{aligned}
$$

Assume that the optimal solution for Model (7) is $\left(\beta_{1}^{*}, u_{r d}^{* 1}, w_{i d}^{* 1}, \forall r, i\right)$. Let $E_{d j}^{* 1}=\frac{\sum_{r=1}^{s} u_{r d}^{* 1} y_{r j}}{\sum_{i=1}^{m} w_{i d}^{* * 1} x_{i j}}, \forall j$, then $J=j \mid j=1,2, . ., n, j \neq d$ can be divided into two mutually incompatible subsets as follows.

$$
\begin{aligned}
& J_{1}=j \mid E_{d j}^{* 1}=\beta_{1}^{*}, \quad \forall j \in J, \\
& J_{2}=j \mid E_{d j}^{* 1}>\beta_{1}^{*}, \quad \forall j \in J .
\end{aligned}
$$

Through Model (7), the peer-efficiency score of DMUs is determined as $\beta_{1}^{*}$. Assume that the number of DMUs in $J_{1}$ is $n_{1}$. If $n_{1}=m+s-2$, then the algorithm terminates and $\left(\beta_{1}^{*}, u_{r d}^{* 1}, w_{r d}^{* 1}, \forall r, i\right)$ is the unique optimal solution for Model (7) (the reason is explained by Theorem 2). If $n_{1}=m+s-2$, then go to Step 2.

Step 2: $l=2$ calculate Model (8) in the following.

$$
\begin{aligned}
& \max _{w, u} \beta \\
& \text { s.t. } \\
& \sum_{r=1}^{s} u_{r d} y_{r j}-\sum_{i=1}^{m} w_{i d} x_{i j} \leq 0, \quad \forall j, \\
& \sum_{r=1}^{s} u_{r d} y_{r d}=E_{d d}, \\
& \sum_{i=1}^{m} w_{i d} x_{i d}=1, \\
& \sum_{r=1}^{s} u_{r d} y_{r j}-\beta_{1}^{*} \cdot \sum_{i=1}^{m} w_{i d} x_{i j}=0, \quad \forall j \in J_{1}, \\
& \sum_{r=1}^{s} u_{r d} y_{r j}-\beta \cdot \sum_{i=1}^{m} w_{i d} x_{i j} \leq 0, \quad \forall j \in J_{2}, \\
& u_{r d}, w_{i d} \geq 0, \quad \forall i, r .
\end{aligned}
$$

Insuring that the self-efficiency score of $\mathrm{DMU}_{d}$ is $E_{d d}$ and the peer-efficiency score of the DMUs in $J_{1}$ is $\beta_{1}^{*}$, the optimal solution for Model (8), denoted by $\left(\beta_{2}^{*}, u_{r d}^{* 2}, w_{i d}^{* 2}, \forall r, i\right)$, can be obtained. Let $E_{d j}^{* 2}=$ $\frac{\sum_{r=1}^{s} u_{r d}^{* 2} y_{r j}}{\sum_{i=1}^{m} w_{i d}^{* 2} x_{i j}}, j \in J_{2} ; J_{2}$ is then divided into two mutually incompatible subsets as follows: 


$$
\begin{aligned}
& J_{3}=j \mid E_{d j}^{* 2}=\beta_{2}^{*}, \quad \forall j \in J_{2}, \\
& J_{4}=j \mid E_{d j}^{* 2}>\beta_{2}^{*}, \quad \forall j \in J_{2} .
\end{aligned}
$$

Using Model (8), the peer-efficiency score of the DMUs in $J_{3}$ is determined as $\beta_{2}^{*}$. Assume that the number of DMUs in $J_{3}$ is $n_{2}$. If $n_{1}+n_{2}=m+s-2$, then the algorithm terminates and $\left(\beta_{2}^{*}, u_{r d}^{* 2}, w_{i d}^{* 2}, \forall r, i\right)$ is the unique optimal solution for Model (8) (the reason is explained by Theorem 2). If $n_{1}+n_{2}<$ $m+s-2$, then go to Step 3 .

Step 3: $l=l+1$; solve Model (9) below:

$$
\begin{aligned}
& \max _{w, u} \beta \\
& \text { s.t. } \\
& \sum_{r=1}^{s} u_{r d} y_{r j}-\sum_{i=1}^{m} w_{i d} x_{i j} \leq 0, \quad \forall j, \\
& \sum_{r=1}^{s} u_{r d} y_{r d}=E_{d d}, \\
& \sum_{i=1}^{m} w_{i d} x_{i d}=1, \\
& \sum_{r=1}^{s} u_{r d} y_{r j}-\beta_{1}^{*} \cdot \sum_{i=1}^{m} w_{i d} x_{i j}=0, \quad \forall j \in J_{1}, \\
& \sum_{r=1}^{s} u_{r d} y_{r j}-\beta_{2}^{*} \cdot \sum_{i=1}^{m} w_{i d} x_{i j}=0, \quad \forall j \in J_{3}, \\
& \ldots \\
& \sum_{r=1}^{s} u_{r d} y_{r j}-\beta_{l-1}^{*} \cdot \sum_{i=1}^{m} w_{i d} x_{i j}=0, \quad \forall j \in J_{2 l-3}, \\
& u_{r d}, w_{i d} \geq 0, \quad \forall i, r . \\
& \sum_{i=1}^{m} w_{i d} x_{i j} \leq 0, \quad \forall j \in J_{2 l-2},
\end{aligned}
$$

Similarly, ensure that the self-efficiency score of $\mathrm{DMU}_{d}$ is $E_{d d}$ and the peer-efficiency scores of the DMUs in $J_{1}, J_{3}, \ldots, J 2 L-3$ are $\beta_{1}^{*}, \ldots, \beta_{l-1}^{*}$, respectively. We can assume that the optimal solution of Model $(9)$ is $\left(\beta_{l}^{*}, u_{r d}^{* l}, w_{i d}^{* l}, \forall r, i\right)$. Let:

$$
E_{d j}^{* l}=\frac{\sum_{r=1}^{s} u_{r d}^{* l} y_{r j}}{\sum_{i=1}^{m} w_{i d}^{* l} x_{i j}}, j \in J_{2 l-2}, J_{2 l-2},
$$

is then divided into two subsets as follows:

$$
J_{2 l-1}=j \mid E_{d j}^{* l}=\beta_{l}^{*}, \quad \forall j \in J_{2 l-2},
$$

$$
J_{2 l}=j \mid E_{d j}^{* l}>\beta_{l}^{*}, \quad \forall j \in J_{2 l-2} .
$$

Using Model (9), the peer-efficiency score of the DMUs in $J_{2 l-1}$ is determined as $\beta_{l}^{*}$. Assume that the number of DMUs in $J_{2 l-1}$ is $n_{l}$. If $\sum_{t=1}^{l}=$ $m+s-2$, then the algorithm terminates, and $\left(\beta_{1}^{*}, u_{r d}^{* l}, w_{i d}^{* l}, \forall r, i\right)$ is the unique optimal solution for Model (9) (the reason is explained by Theorem 2). If $\sum_{t=1}^{l}<m+s-2$, then go to Step 3 again.

Assume that the above steps are repeated $k$ times $(k \leq n-1)$. The peer-efficiency scores of $\mathrm{DMU}_{j}, \forall j, j \neq$ $d$, denoted by $E_{d j} *$, can be obtained as follows:

$$
\begin{aligned}
& E_{d j}^{*}=\beta_{1}^{*}, j \in J_{1}, \\
& E_{d j}^{*}=\beta_{2}^{*}, j \in J_{3}, \\
& \ldots \\
& E_{d j}^{*}=\beta_{k}^{*}, j \in J_{2 k-1} .
\end{aligned}
$$

Theorem 1. The optimal weights of Model (8) are also the optimal weights of Model (7). Also, the optimal value of Model (8) is larger than the optimal value of Model (7).

Proof: The optimal solution for Model (7) is $\left(\beta_{1}^{*}, u_{r d}^{* 1}, w_{i d}^{* 1}, \forall i, r\right)$ and we have:

$$
\frac{\sum_{r=1}^{s} u_{r d}^{* 1} y_{r j}}{\sum_{i=1}^{m} w_{i d}^{* 1} x_{i j}}=\beta_{1}^{*} \quad\left(j \in J_{1}\right),
$$

and:

$$
\frac{\sum_{r=1}^{s} u_{r d}^{* 1} y_{r j}}{\sum_{i=1}^{m} w_{i d}^{* 1} x_{i j}}>\beta_{1}^{*} \quad\left(j \in J_{2}\right) .
$$

The optimal solution for Model (8) is $\left(\beta_{2}^{*}, u_{r d}^{* 2}, w_{i d}^{* 2}\right.$, $\forall i, r)$ and we have:

$$
\frac{\sum_{r=1}^{s} u_{r d}^{* 2} y_{r j}}{\sum_{i=1}^{m} w_{i d}^{* 2} x_{i j}}=\beta_{1}^{*} \quad\left(j \in J_{1}\right),
$$

and:

$$
\frac{\sum_{r=1}^{s} u_{r d}^{* 2} y_{r j}}{\sum_{i=1}^{m} w_{i d}^{* 2} x_{i j}}>\beta_{2}^{*} \quad\left(j \in J_{2}\right) .
$$

Obviously, $\beta_{2}^{*} \geq \beta_{1}^{*}$. Assuming that $\beta_{1}^{*} \geq \beta_{1}^{*}$, we have $J_{3} \subseteq J_{1}$, which conflicts with the fact that $J_{3} \subseteq J_{2}$ and $J_{2} \cap J_{1}=\Phi$. Thus, we have $\beta_{2}^{*}>\beta_{1}^{*}$. Through the optimal solution $\left(\beta_{2}^{*}, u_{r d}^{* 2}, w_{i d}^{* 2}, \forall i, r\right)$ obtained by Model (8), the optimal value of Model (7) is $\beta_{1}^{*}$. Therefore, the optimal solutions for Model (7) is the optimal solution for Model (8), and the optimal solution for Model (8) is the optimal solution for Model (7). Q.E.D. 
Through Theorem 1, we know that the optimal weights of Model (9) with $l=k$ are also the optimal weights of Model $(7)$, and $\beta_{k}^{*}>\beta_{k-1}^{*}>\ldots>\beta_{1}^{*}$.

Theorem 2. If $n_{1}=m+s-2$, then $\left(\beta_{1}^{*}, u_{r d}^{* l}, w_{i d}^{* l}\right.$, $\forall i, r, j)$ is the unique optimal solution of Model (7).

Proof: For Model (7), if $n_{1}=m+s-2$, we know that $\sum_{r=1}^{s} u_{r d} y_{r j}-\beta_{1}^{*} \cdot \sum_{i=1}^{m} w_{i d} x_{i j}=0, \forall j \in J_{1}$. Note that Model (7) contains two equations, $\sum_{i=1}^{m} w_{i d} x_{i d}=1$ and $\sum_{r=1}^{s} u_{r d} y_{r d}=E_{d d}$. The number of variables $\left(u_{r d}, w_{i d}, \forall r, i\right)$ is $m+s$, and the vectors $\left(x_{i j}, y_{r j}, \forall i, r, j\right)$ are mutually linearly independent. Because the number of variables and equations are both $m+s$, the optimal solution for Model ( 7 ) can be uniquely determined and denoted by $\left(\beta_{1}^{*}, u_{r d}^{* 1}, w_{i d}^{* 1}, \forall r, i, d\right)$ and the algorithm terminates. If $n_{1}<m+s-2$, then go to Step 2. Q.E.D.

Through Theorem 2, we know that if $\sum_{t=1}^{l} n_{t}=$ $m+s-2$, then $\left(\beta_{1}^{*}, u_{r d}^{* 1}, w_{i d}^{* 1}, \forall r, i\right)$ is the unique optimal solution for Model (9), and the algorithm terminates.

\subsection{The exclusiveness cross-efficiency model}

If the evaluated DMU is competing with other DMUs, the secondary goal of the evaluated DMUs should be minimizing the peer-efficiency scores of all other DMUs as much as possible. Therefore, the exclusiveness crossefficiency model is presented to cope with this situation. This model is shown as follows:

$$
\begin{aligned}
& \min _{w, u} \max _{1 \leq j \leq n, j \neq d} E_{d j}=\frac{\sum_{r=1}^{s} u_{r d} y_{r j}}{\sum_{i=1}^{m} w_{i d} x_{i j}} \\
& \text { s.t. } \\
& \sum_{r=1}^{s} u_{r d} y_{r j}-\sum_{i=1}^{m} w_{i d} x_{i j} \leq 0, \quad \forall j, \\
& \sum_{r=1}^{s} u_{r d} y_{r d}=E_{d d}, \\
& \sum_{i=1}^{m} w_{i d} x_{i d}=1, \\
& u_{r d}, w_{i d} \geq 0, \quad \forall i, r .
\end{aligned}
$$

The minimum peer-efficiency score of $\mathrm{DMU}_{j}(j=$ $1,2, \ldots, n)$ as evaluated by $\mathrm{DMU}_{d}$ can be obtained through Model (10), while $\mathrm{DMU}_{d}$ is retained as the optimal self-efficiency score. Model (10) is also a multiobjective programming model. The first objective of the models is to identify the DMU with the maximal peer-efficiency score among all the DMUs. The second objective is to minimize the maximal peer-efficiency score through the weights of $\mathrm{DMU}_{d}$.

The corresponding steps are designed to find the solution for Model (10).
Step 1: let $l=1$,; translate Model (10) into Model (11) as follows:

$$
\begin{aligned}
& \min _{w, u} \alpha \\
& \text { s.t. } \\
& \sum_{r=1}^{s} u_{r d} y_{r j}-\sum_{i=1}^{m} w_{i d} x_{i j} \leq 0, \quad \forall j, \\
& \sum_{r=1}^{s} u_{r d} y_{r d}=E_{d d}, \\
& \sum_{i=1}^{m} w_{i d} x_{i d}=1, \\
& \sum_{r=1}^{s} u_{r d} y_{r j}-\alpha \cdot \sum_{i=1}^{m} w_{i d} x_{i j} \leq 0, \quad \forall j, j \neq d, \\
& u_{r d}, w_{i d} \geq 0, \quad \forall i, r .
\end{aligned}
$$

Suppose that the optimal solution for Model (11) is $\left(\alpha_{1}^{*}, u_{r d}^{* 1}, w_{i d}^{* 1}, \forall r, i\right)$. Let:

$$
E_{d j}^{* 1}=\frac{\sum_{r=1}^{s} u_{r d}^{* 1} y_{r j}}{\sum_{i=1}^{m} w_{i d}^{* 1} x_{i j}}, \quad \forall j, \quad j \neq d .
$$

$J=j \mid j=1,2, . ., n, j \neq d$ is then divided into two incompatible subsets:

$$
\begin{aligned}
& J_{1}=j \mid E_{d j}^{* 1}=\alpha_{1}^{*}, \quad \forall j \in J, \\
& J_{2}=j \mid E_{d j}^{* 1}>\alpha_{1}^{*}, \quad \forall j \in J .
\end{aligned}
$$

Using Model (11), the peer-efficiency score of DMUs in $J_{1}$ is determined as $\alpha_{1}^{*}$. Assume that the number of DMUs in $J_{1}$ is $n_{1}$. If $n_{1}=m+s-2$, then the algorithm terminates and $\left(\alpha_{1}^{*}, u_{r d}^{* 1}, w_{r d}^{* 1}, \forall r, i\right)$ is the unique optimal solution for Model (11) (the reason is explained by Theorem 4). If $n_{1}=m+s-2$, then go to Step 2.

Step 2: $l=2$; solve Model (12) below:

$$
\begin{aligned}
& \min _{w, u} \alpha \\
& \text { s.t. } \\
& \sum_{r=1}^{s} u_{r d} y_{r j}-\sum_{i=1}^{m} w_{i d} x_{i j} \leq 0, \quad \forall j, \\
& \sum_{r=1}^{s} u_{r d} y_{r d}=E_{d d}, \\
& \sum_{i=1}^{m} w_{i d} x_{i d}=1,
\end{aligned}
$$




$$
\begin{aligned}
& \sum_{r=1}^{s} u_{r d} y_{r j}-\alpha_{1}^{*} \cdot \sum_{i=1}^{m} w_{i d} x_{i j}=0, \quad \forall j \in J_{1}, \\
& \sum_{r=1}^{s} u_{r d} y_{r j}-\alpha \cdot \sum_{i=1}^{m} w_{i d} x_{i j} \leq 0, \quad \forall j \in J_{2}, \\
& u_{r d}, w_{i d} \geq 0, \quad \forall i, r .
\end{aligned}
$$

Ensure that the self-efficiency score of $\mathrm{DMU}_{d}$ is $E_{d d}$ and the peer-efficiency score of the DMUs in $J_{1}$ is $\alpha_{1}^{*}$. Suppose that the optimal solution for Model (12) is $\left(\alpha_{2}^{*}, u_{r d}^{* 2}, w_{i d}^{* 2}, \forall r, i\right)$. Let $E_{d j}^{* 2}=\frac{\sum_{r=1}^{s} u_{r d}^{* 2} y_{r j}}{\sum_{i=1}^{m} w_{i d}^{* 2} x_{i j}}, j \in J_{2}$; $J_{2}$ is then divided into two subsets as follows:

$$
\begin{aligned}
& J_{3}=j \mid E_{d j}^{* 2}=\alpha_{2}^{*}, \quad \forall j \in J_{2}, \\
& J_{4}=j \mid E_{d j}^{* 2}>\alpha_{2}^{*}, \quad \forall j \in J_{2} .
\end{aligned}
$$

Using Model (12), the peer-efficiency score of the DMUs in $J_{3}$ is determined as $\alpha_{2}^{*}$. Assume that the number of DMUs in $J_{3}$ is $n_{2}$. If $n_{1}+n_{2}=m+s-2$, then the algorithm terminates and $\left(\alpha_{2}^{*}, u_{r d}^{* 2}, w_{i d}^{* 2}, \forall r, i\right)$ is the unique optimal solution for Model (12) (the reason is explained by Theorem 4). If $n_{1}+n_{2}<$ $m+s-2$, then go to Step 3 .

Step 3: $l=l+1$; solve the general Model (13) in the following:

$\max _{w, u} \alpha$

s.t.

$\sum_{r=1}^{s} u_{r d} y_{r j}-\sum_{i=1}^{m} w_{i d} x_{i j} \leq 0, \quad \forall j$,

$\sum_{r=1}^{s} u_{r d} y_{r d}=E_{d d}$

$\sum_{i=1}^{m} w_{i d} x_{i d}=1$

$\sum_{r=1}^{s} u_{r d} y_{r j}-\alpha_{1}^{*} \cdot \sum_{i=1}^{m} w_{i d} x_{i j}=0, \quad \forall j \in J_{1}$,

$\sum_{r=1}^{s} u_{r d} y_{r j}-\alpha_{2}^{*} \cdot \sum_{i=1}^{m} w_{i d} x_{i j}=0, \quad \forall j \in J_{3}$,

$\sum_{r=1}^{s} u_{r d} y_{r j}-\alpha_{l-1}^{*} \cdot \sum_{i=1}^{m} w_{i d} x_{i j}=0, \quad \forall j \in J_{2 l-3}$,

$\sum_{r=1}^{s} u_{r d} y_{r j}-\alpha \cdot \sum_{i=1}^{m} w_{i d} x_{i j} \leq 0, \quad \forall j \in J_{2 l-2}$, $u_{r d}, w_{i d} \geq 0, \quad \forall i, r$.

Ensure that the self-efficiency score of $\mathrm{DMU}_{d}$ is $E_{d d}$, and the peer-efficiency scores of the DMUs in $J_{1}, J_{3}, \ldots, J_{2 L-3}$ are $\alpha_{1}^{*}, \ldots, \alpha_{l-1}^{*}$, respectively. Suppose the optimal solution for Model (13) is $\left(\alpha_{l}^{*}, u_{r d}^{* l}, w_{i d}^{* l}, \forall r, i\right)$. Let $E_{d j}^{* l}=\frac{\sum_{r=1}^{s} u_{r d}^{* l} y_{r j}}{\sum_{i=1}^{m} w_{i d}^{* l} x_{i j}}, j \in J_{2 l-2}$; $J_{2 l-2}$ is then divided into two subsets as follows:

$$
\begin{aligned}
& J_{2 l-1}=j \mid E_{d j}^{* l}=\alpha_{l}^{*}, \quad \forall j \in J_{2 l-2}, \\
& J_{2 l}=j \mid E_{d j}^{* l}>\alpha_{l}^{*}, \quad \forall j \in J_{2 l-2} .
\end{aligned}
$$

Using Model (13), the peer-efficiency score of the DMUs in $J_{2 l-1}$ is determined as $\alpha_{l}^{*}$. Assume that the number of DMUs in $J_{2 l-1}$ is $n_{l}$. If $\sum_{t=1}^{l}=m+s-2$, then the algorithm terminates, and $\left(\alpha_{1}^{*}, u_{r d}^{* l}, w_{i d}^{* l}, \forall r, i\right)$ is the unique optimal solution for Model (9) (the reason is explained by Theorem 4). If $\sum_{t=1}^{l}<m+s-2$, then go to Step 3.

Assume that the above steps are repeated $w$ times $(w \leq n-1)$. The peer-efficiency scores of $\mathrm{DMU}_{j}, \forall j, \bar{j} \neq d$, denoted as $E_{d j} *$, can be obtained as follows:

$$
\begin{aligned}
& E_{d j}^{*}=\alpha_{1}^{*}, j \in J_{1}, \\
& E_{d j}^{*}=\alpha_{2}^{*}, j \in J_{3}, \\
& \ldots \\
& E_{d j}^{*}=\alpha_{k}^{*}, j \in J_{2 k-1} .
\end{aligned}
$$

Theorem 3. The optimal weights of Model (12) are also the optimal weights of Model (11) and the optimal value of Model (12) is smaller than the optimal value of Model (11).

Proof: The proof for this theorem is similar to that for Theorem 1 hence, it is not provided again.

Through Theorem 3, we know that the optimal weights of Model (13), while $l=2$, are also the optimal weights of Model (11), and $\alpha_{w}^{*}<\alpha_{2-1}^{*}<\ldots<\alpha_{1}^{*}$.

Theorem 4. If $n_{1}=m+s-2$, then $\left(\alpha_{1}^{*}, u_{r d}^{* l}, w_{i d}^{* l}, \forall i, r\right)$ is the unique optimal solution for Model (11).

Proof: The proof for this theorem is similar to Theorem 2; hence, it is not provided again.

Through Theorem 4, we know that if $\sum_{t=1}^{l} n_{t}=$ $m+s-2$, then $\left(\alpha_{1}^{*}, u_{r d}^{* 1}, w_{i d}^{* 1}, \forall r, i, j\right)$ is the unique optimal solution for Model (9), and the algorithm terminates.

\subsection{Solution method}

It can be easily observed that the altruism crossefficiency and exclusiveness cross-efficiency models 
have some properties in common, which allow them to be solved using similar methods. Here, we give an algorithm to solve the proposed altruism cross-efficiency model. Based on the algorithm, the exclusiven ess crossefficiency model can also be solved. The workflow of the algorithm in provided in Figure 1.

This method notes that $\beta$ is a parameter, and Models (7), (8), and (9) should be solved as parametric linear programming ones.

The following steps explicitly describes how the altruism cross-efficiency model (i.e., Model (6)) can be solved by solving Models (7), (8), and (9):

Step 1: Solve Model (7). In Model (7), the initial value of $\beta$ is set to min $E_{d j}, \forall j$. Then, every time $\beta$ increases by a small positive number, e.g., $\delta=0.0001$, the increased times are denoted by $I$. Thus, $\beta=$ min $E_{d j}, \forall j+I \delta$ and $I=0,1,2, \ldots$. Assume that when $I=I_{1}^{*}$, Model (7) has no feasible solutions. The optimal value of Model (7) can be obtained, which is $\beta_{1}^{*}=\min E_{d j}, \forall j+\left(I_{1}^{*}-1\right) \delta$. If $n_{1}=m+S-2$, then the algorithm terminates and $\left(\beta_{1}^{*}, u_{r d}^{* l}, w_{i d}^{* l}, \forall i, r\right)$ is the unique optimal solution for Model (7). If $n_{1}<$ $m+S-2$, then go to Step 2 .

Step 2: Solve Model (8). Since the optimal value of Model (8) is larger than that of Model (7), the initial value of $\beta$ in Model (8) is set to $\min E_{d j}, \forall j+I_{1}^{*} \delta$. Therefore, $\beta=\min E_{d j}, \forall j+I \delta$, and $I=I_{1}^{*}, I_{1}^{*}+$ $1, I_{1}^{*}+2, \ldots$. Assume that when $I=I_{2}^{*}$, Model (8) has no feasible solutions. The optimal value of Model (8) can be obtained, is $\beta_{2}^{*}=\min E_{d j}, \forall j+\left(I_{2}^{*}-1\right) \delta$. If $n_{1}+n_{1}=m+S-2$, then the algorithm terminates, and $\left(\beta_{2}^{*}, u_{r d}^{* 2}, w_{i d}^{* 2}, \forall i, r\right)$ is the unique optimal solution for Model (8). If $n_{1}+n_{1}<m+S-2$, go to Step 3 .

Step 3: Solve Model (9). Generally, in Model (9), the initial value of $\beta$ is set to $\min E_{d j}, \forall j+I_{l-1}^{*} \delta$. Thus $\beta=\min E_{d j}, \forall j+I \delta$ and $I=I_{l-1}^{*}, I_{l-1}^{*}+1, I_{l-1}^{*}+2, \ldots$. Assume that when $I=I_{l}^{*}$, Model (9) has no feasible solutions. The optimal value of Model (9) can be obtained, which is $\beta_{l}^{*}=\min E_{d j}, \forall j+\left(I_{l}^{*}-1\right) \delta$. If $\sum_{t=1}^{l} n_{t}<m+S-2$, repeat Step 3 again until we have $\sum_{t=1}^{l} n_{t}=m+S-2$.

\section{Numerical example}

In this section, two numerical examples are used to verify effectiveness and feasibility of the proposed models.

\subsection{A simple example of five DMUs}

Firstly, as shown in Table 2, there are five DMUs with three inputs (X1, X2, X3) and two outputs (Y1, Y2) to be evaluated.

Five DMUs are evaluated by the CCR model (Model (1)), the traditional cross-efficiency model (Model (2)), the traditional benevolent model (Model (4)), and the proposed altruism model. Table 3 shows the average efficiency scores and ranking orders for the DMUs, as obtained through each different model. The cross-efficiency scores for each DMU from Models (2), (4), and (6) are given in Tables 4, 5, and 6, respectively. As shown in the second column of Table 3, four DMUs

Table 2. A simple numerical example.

\begin{tabular}{cccccc}
\hline DMUs & X1 & X2 & X3 & Y1 & Y2 \\
\hline DMU1 & 7 & 1 & 2 & 9 & 9 \\
DMU2 & 5 & 2 & 1 & 7 & 7 \\
DMU3 & 4 & 3 & 2 & 5 & 7 \\
DMU4 & 5 & 6 & 1 & 6 & 2 \\
DMU5 & 6 & 7 & 1 & 9 & 6 \\
\hline
\end{tabular}

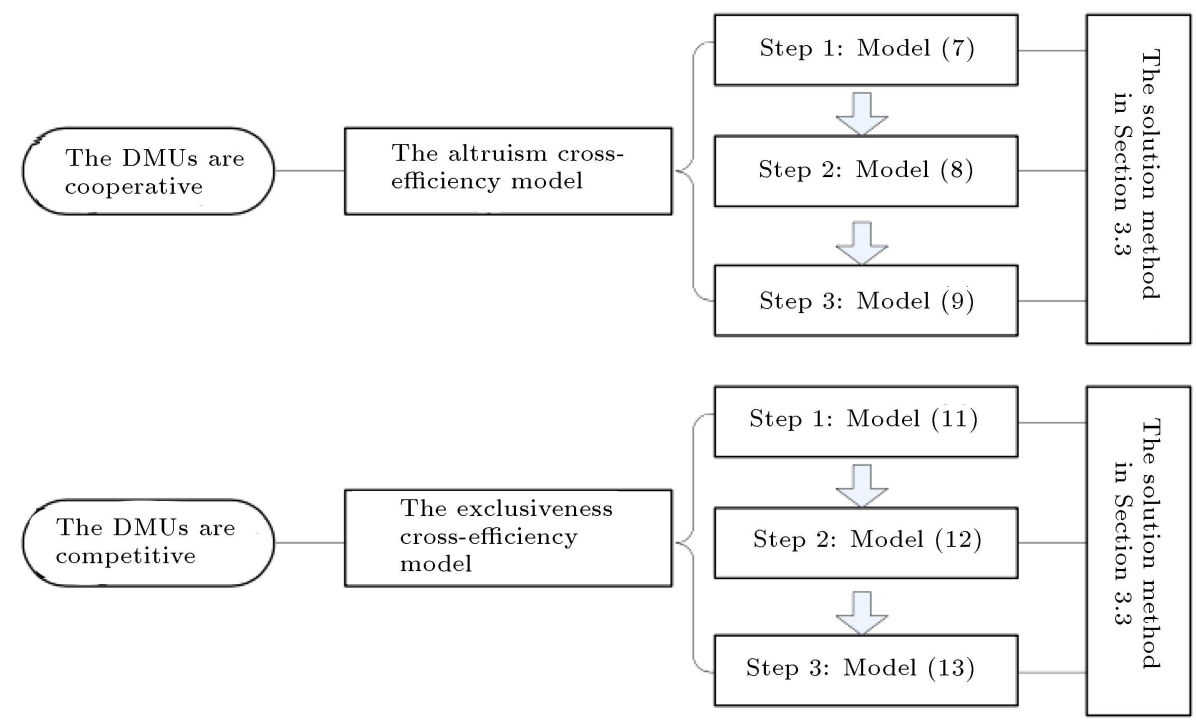

Figure 1. Workflow of the algorithm. 
Table 3. Efficiency scores and rankings of different models.

\begin{tabular}{ccccccccc}
\hline DMU & $\begin{array}{c}\text { CCR } \\
\text { model }\end{array}$ & Rank & $\begin{array}{c}\text { Classical } \\
\text { model }\end{array}$ & Rank & $\begin{array}{c}\text { Benevolent } \\
\text { model }\end{array}$ & Rank & $\begin{array}{c}\text { Altruism } \\
\text { model }\end{array}$ & Rank \\
\hline 1 & 1.000 & 1 & 0.856 & 1 & 0.927 & 3 & 0.930 & 3 \\
2 & 1.000 & 1 & 0.846 & 2 & 0.987 & 1 & 0.986 & 1 \\
3 & 1.000 & 1 & 0.588 & 4 & 0.893 & 4 & 0.877 & 4 \\
4 & 0.800 & 5 & 0.416 & 5 & 0.742 & 5 & 0.750 & 5 \\
5 & 1.000 & 1 & 0.652 & 3 & 0.965 & 2 & 0.964 & 2 \\
\hline
\end{tabular}

Table 4. Arbitrary cross-efficiency scores.

\begin{tabular}{cccccc}
\hline \multirow{2}{*}{ Rating } & \multicolumn{5}{c}{ Rated $\mathbf{D M U}_{\boldsymbol{j}}$} \\
\cline { 2 - 6 } & $\mathbf{1}$ & $\mathbf{2}$ & $\mathbf{3}$ & $\mathbf{4}$ & $\mathbf{5}$ \\
\hline 1 & 1.000 & 0.443 & 0.249 & 0.103 & 0.152 \\
2 & 0.894 & 1.000 & 0.513 & 0.295 & 0.542 \\
3 & 0.932 & 0.965 & 1.000 & 0.224 & 0.566 \\
4 & 0.857 & 0.933 & 0.833 & 0.800 & 1.000 \\
5 & 0.595 & 0.889 & 0.343 & 0.658 & 1.000 \\
\hline
\end{tabular}

Table 5. Cross-efficiency scores of Model (4).

\begin{tabular}{cccccc}
\hline \multirow{2}{*}{ Rating } & \multicolumn{5}{c}{ Rated DMU $_{\boldsymbol{j}}$} \\
\cline { 2 - 6 } & $\mathbf{1}$ & $\mathbf{2}$ & $\mathbf{3}$ & $\mathbf{4}$ & $\mathbf{5}$ \\
\hline 1 & 1.000 & 1.000 & 0.804 & 0.684 & 0.862 \\
2 & 0.941 & 1.000 & 0.865 & 0.798 & 1.000 \\
3 & 0.918 & 1.000 & 1.000 & 0.686 & 0.964 \\
4 & 0.857 & 0.933 & 0.833 & 0.800 & 1.000 \\
5 & 0.918 & 1.000 & 0.964 & 0.743 & 1.000 \\
\hline
\end{tabular}

Table 6. Cross-efficiency scores of the proposed altruism model.

\begin{tabular}{cccccc}
\hline \multirow{2}{*}{ Rating DMU $_{\boldsymbol{d}}$} & \multicolumn{5}{c}{ Rated DMU } \\
\cline { 2 - 6 } & $\mathbf{1}$ & $\mathbf{2}$ & $\mathbf{3}$ & $\mathbf{4}$ & $\mathbf{5}$ \\
\hline 1 & 1.000 & 1.000 & 0.803 & 0.682 & 0.861 \\
2 & 0.939 & 1.000 & 0.873 & 0.793 & 0.999 \\
3 & 0.918 & 1.000 & 1.000 & 0.682 & 0.961 \\
4 & 0.857 & 0.933 & 0.833 & 0.800 & 1.000 \\
5 & 0.936 & 0.998 & 0.874 & 0.792 & 1.000 \\
\hline
\end{tabular}

are evaluated as being efficient. This clearly indicates that DMUs cannot be effectively distinguished by the CCR model. In order to overcome this defect, the crossefficiency evaluation is carried out for Models (2) and (4) as well as the proposed altruism model. It is observed that the diagonal elements of Tables 4, 5, and 6 , i.e. the self-efficiency scores of the DMUs, are identical, as obtained by the CCR model. In addition, the peerefficiency scores from Model (2) are generally smaller than those from Models (4) and (6). For instance, the peer-efficiency scores of DMU1, as evaluated by
DMU5 in Models (2), (4), and the proposed altruism model, are $0.595,0.918$, and 0.936 , respectively. No large differences exist between the peer-efficiency scores of Models (4) and (6). This is because the main function of both model (4) and the altruism model is to maximize the peer-efficiency scores of the other DMUs, while simultaneously ensuring optimality of the selfefficiency score of the evaluated DMU. However, the main difference between Model (4) and the altruism model lies in the following two aspects. On the one hand, Model (4) has the objective of maximizing the average efficiency of other $n-1$ DMUs, while the altruism model is supposed to maximize/minimize the efficiency of each of the other $n-1$ DMUs. On the other hand, the altruism model can obtain a unique set of cross-efficiency scores, while Model (4) fails to do that.

\subsection{Application to flexible manufacturing systems}

The numerical example from Shang and Sueyoshi [8] is then used to illustrate the proposed models. As shown in Table 7, there are 12 Flexible Manufacturing Systems (FMSs) to be evaluated. Each FMS contains two inputs and four outputs:

Input 1: The annual operating and depreciation cost $(\$ 100,000)$;

Input 2: The floor space requirements of each specific system $\left(1000 \mathrm{ft}^{2}\right)$;

Output 1: Improvements in qualitative benefits (\%);

Output 2: Work in-process reduced (10);

Output 3: Average reduction in the number of tardy jobs $(\%)$;

Output 4: Average increase in yield (\%).

The 12 DMUs are evaluated by the CCR model (Model (1)), the traditional cross-efficiency model (Model (2)), the traditional benevolent model (Model (4)), the traditional aggressive model (Model (5)), the proposed altruism model and the proposed exclusiveness model. The corresponding results are reported in Table 8. Using Model (1), the CCR efficiency scores of the DMUs and the corresponding ranking order are 
Table 7. Data on 12 flexible manufacturing systems.

\begin{tabular}{ccccccc}
\hline \multirow{2}{*}{ DMUs } & \multicolumn{7}{c}{ Data } \\
\cline { 2 - 7 } & Input 1 & Input 2 & Output 1 & Output 2 & Output 3 & Output 4 \\
\hline 1 & 17.02 & 5 & 42 & 45.3 & 14.2 & 30.1 \\
2 & 16.46 & 4.5 & 39 & 40.1 & 13 & 29.8 \\
3 & 11.76 & 6 & 26 & 39.6 & 13.8 & 24.5 \\
4 & 10.52 & 4 & 22 & 36 & 11.3 & 25 \\
5 & 9.5 & 3.8 & 21 & 34.2 & 12 & 20.4 \\
6 & 4.79 & 5.4 & 10 & 20.1 & 5 & 16.5 \\
7 & 6.21 & 6.2 & 14 & 26.5 & 7 & 19.7 \\
8 & 11.12 & 6 & 25 & 35.9 & 9 & 24.7 \\
9 & 3.67 & 8 & 4 & 17.4 & 0.1 & 18.1 \\
10 & 8.93 & 7 & 16 & 34.3 & 6.5 & 20.6 \\
11 & 17.74 & 7.1 & 43 & 45.6 & 14 & 31.1 \\
12 & 14.85 & 6.2 & 27 & 38.7 & 13.8 & 25.4 \\
\hline
\end{tabular}

Table 8. Efficiency scores and rankings of different models

\begin{tabular}{|c|c|c|c|c|c|c|c|c|c|c|c|c|}
\hline DMU & $\begin{array}{l}\text { CCR } \\
\text { model }\end{array}$ & Rank & $\begin{array}{c}\text { Classical } \\
\text { model }\end{array}$ & Rank & $\begin{array}{c}\text { Benevolent } \\
\text { model }\end{array}$ & Rank & $\begin{array}{c}\text { Aggressive } \\
\text { model }\end{array}$ & Rank & $\begin{array}{c}\text { Altruism } \\
\text { model }\end{array}$ & Rank & $\begin{array}{c}\text { Exclusiveness } \\
\text { model }\end{array}$ & Rank \\
\hline 1 & 1.000 & 1 & 0.870 & 3 & 0.955 & 5 & 0.848 & 3 & 0.947 & 5 & 0.842 & 4 \\
\hline 2 & 1.000 & 1 & 0.857 & 4 & 0.936 & 6 & 0.839 & 4 & 0.930 & 6 & 0.830 & 5 \\
\hline 3 & 0.982 & 9 & 0.819 & 5 & 0.925 & 8 & 0.779 & 5 & 0.919 & 8 & 0.827 & 6 \\
\hline 4 & 1.000 & 1 & 0.890 & 2 & 0.981 & 2 & 0.857 & 2 & 0.982 & 2 & 0.884 & 2 \\
\hline 5 & 1.000 & 1 & 0.911 & 1 & 0.977 & 3 & 0.878 & 1 & 0.972 & 3 & 0.894 & 1 \\
\hline 6 & 1.000 & 1 & 0.762 & 9 & 0.956 & 4 & 0.729 & 8 & 0.958 & 4 & 0.825 & 7 \\
\hline 7 & 1.000 & 1 & 0.797 & 6 & 0.988 & 1 & 0.760 & 6 & 0.988 & 1 & 0.856 & 3 \\
\hline 8 & 0.961 & 10 & 0.764 & 8 & 0.931 & 7 & 0.723 & 9 & 0.927 & 7 & 0.793 & 8 \\
\hline 9 & 1.000 & 1 & 0.560 & 12 & 0.749 & 12 & 0.571 & 12 & 0.762 & 12 & 0.630 & 12 \\
\hline 10 & 0.954 & 11 & 0.653 & 11 & 0.815 & 10 & 0.624 & 11 & 0.812 & 10 & 0.696 & 10 \\
\hline 11 & 0.983 & 8 & 0.776 & 7 & 0.908 & 9 & 0.739 & 7 & 0.899 & 9 & 0.780 & 9 \\
\hline 12 & 0.801 & 12 & 0.701 & 10 & 0.773 & 11 & 0.671 & 10 & 0.770 & 11 & 0.695 & 11 \\
\hline
\end{tabular}

obtained and shown in the second and third columns of Table 8. Note that there are seven efficient DMUs, which cannot be further distinguished by Model (1).

From Table 8 , we find out that the average cross-efficiency scores calculated by Model (4) and the altruism model are larger than those calculated by Model (5) and the exclusiveness model. This is because the intended objective of Model (4) and the altruism model is to maximize peer-efficiency scores of other DMUs. Conversely, the key objective of both Model (5) and the exclusiveness model is to minimize the peerefficiency scores of other DMUs.

The 11th and 13th columns of Table 8 present the ranking orders of DMUs as obtained by the altruism model and the exclusiveness model, respectively. We can see that these two ranking orders are totally different. For example, DMU7 is ranked in first by the altruism model, whereas the same DMU is ranked in third by the exclusiveness model. This indicates that different strategies will lead to different ranking results. Therefore, the decision makers should choose the appropriate model, according to the actual application.

Tables 9, 10, and 11 list the cross-efficiency scores obtained by Model (1), the altruism model, and the exclusiveness model, respectively. The diagonal elements in the tables provide the self-efficiency scores of the DMUs as obtained from Model (1). By comparing the cross-efficiency scores, we reach several findings. Firstly, the peer-efficiency scores from the altruism model (or the exclusiveness model) are larger (or smaller) than those from Model (2). For example, the peer-efficiency scores of DMU1, as evaluated by DMU5 in Model (2), the altruism model, and the exclusiveness model, are $0.879,0.958$, and 0.747 , respectively. This indicates that the proposed altruism model (or exclusiveness model) has a good ability to maximize (or minimize) the peer-efficiency scores of other DMUs. Therefore, both the altruism and the exclusiveness models can be considered as an extension of the traditional cross- efficiency evaluation methods. Secondly, the standard deviations of the cross-efficiency 
Table 9. The arbitrary cross-efficiency scores.

\begin{tabular}{ccccccccccccc}
\hline Rating & \multicolumn{10}{c}{ Rated $_{\text {DMU }}$. } \\
\cline { 2 - 12 } DM $_{\boldsymbol{d}}$ & $\mathbf{1}$ & $\mathbf{2}$ & $\mathbf{3}$ & $\mathbf{4}$ & $\mathbf{5}$ & $\mathbf{6}$ & $\mathbf{7}$ & $\mathbf{8}$ & $\mathbf{9}$ & $\mathbf{1 0}$ & $\mathbf{1 1}$ & $\mathbf{1 2}$ \\
\hline 1 & 1.000 & 0.999 & 0.692 & 0.833 & 0.854 & 0.371 & 0.434 & 0.635 & 0.142 & 0.426 & 0.787 & 0.650 \\
2 & 0.977 & 1.000 & 0.618 & 0.784 & 0.782 & 0.322 & 0.373 & 0.572 & 0.130 & 0.361 & 0.736 & 0.600 \\
3 & 1.000 & 0.959 & 0.982 & 0.927 & 1.000 & 0.932 & 1.000 & 0.927 & 0.422 & 0.760 & 0.977 & 0.801 \\
4 & 0.955 & 0.981 & 0.784 & 1.000 & 0.990 & 0.501 & 0.550 & 0.676 & 0.257 & 0.490 & 0.746 & 0.736 \\
5 & 0.879 & 0.879 & 0.775 & 0.925 & 1.000 & 0.398 & 0.463 & 0.572 & 0.095 & 0.401 & 0.671 & 0.719 \\
6 & 0.707 & 0.699 & 0.837 & 0.882 & 0.889 & 1.000 & 0.991 & 0.767 & 0.891 & 0.731 & 0.679 & 0.685 \\
7 & 0.683 & 0.661 & 0.871 & 0.884 & 0.932 & 0.990 & 1.000 & 0.747 & 0.779 & 0.745 & 0.654 & 0.700 \\
8 & 1.000 & 0.977 & 0.949 & 1.000 & 1.000 & 0.962 & 1.000 & 0.961 & 0.753 & 0.833 & 0.951 & 0.794 \\
9 & 0.470 & 0.472 & 0.538 & 0.592 & 0.557 & 0.793 & 0.751 & 0.554 & 1.000 & 0.558 & 0.462 & 0.441 \\
10 & 0.764 & 0.704 & 0.904 & 0.956 & 1.000 & 0.951 & 1.000 & 0.860 & 0.849 & 0.954 & 0.714 & 0.720 \\
11 & 1.000 & 0.966 & 0.924 & 0.896 & 0.927 & 0.954 & 1.000 & 0.945 & 0.672 & 0.783 & 0.983 & 0.759 \\
12 & 1.000 & 0.984 & 0.953 & 1.000 & 1.000 & 0.967 & 1.000 & 0.950 & 0.724 & 0.795 & 0.953 & 0.801 \\
\hline Standard & 0.167 & 0.169 & 0.136 & 0.111 & 0.127 & 0.265 & 0.253 & 0.154 & 0.316 & 0.188 & 0.154 & 0.167 \\
deviation & & & & & & & & & & & & \\
\hline
\end{tabular}

Table 10. Cross-efficiency scores of the altruism model.

\begin{tabular}{|c|c|c|c|c|c|c|c|c|c|c|c|c|}
\hline \multirow{2}{*}{$\begin{array}{l}\text { Rating } \\
\text { DMU }_{d}\end{array}$} & \multicolumn{12}{|c|}{ Rated $\mathrm{DMU}_{j}$} \\
\hline & 1 & 2 & 3 & 4 & 5 & 6 & 7 & 8 & 9 & 10 & 11 & 12 \\
\hline 1 & 1.000 & 0.984 & 0.938 & 1.000 & 0.986 & 0.971 & 1.000 & 0.960 & 0.779 & 0.816 & 0.951 & 0.791 \\
\hline 2 & 1.000 & 1.000 & 0.889 & 1.000 & 0.963 & 0.850 & 0.881 & 0.911 & 0.640 & 0.734 & 0.923 & 0.771 \\
\hline 3 & 1.000 & 0.959 & 0.982 & 0.926 & 1.000 & 0.930 & 0.999 & 0.926 & 0.416 & 0.759 & 0.977 & 0.801 \\
\hline 4 & 0.977 & 0.966 & 0.926 & 1.000 & 0.978 & 0.977 & 1.000 & 0.948 & 0.810 & 0.816 & 0.925 & 0.780 \\
\hline 5 & 0.958 & 0.930 & 0.938 & 1.000 & 1.000 & 0.964 & 1.000 & 0.943 & 0.781 & 0.851 & 0.904 & 0.781 \\
\hline 6 & 0.915 & 0.920 & 0.887 & 1.000 & 0.945 & 1.000 & 1.000 & 0.919 & 0.910 & 0.802 & 0.865 & 0.756 \\
\hline 7 & 0.971 & 0.957 & 0.927 & 1.000 & 0.981 & 0.976 & 1.000 & 0.947 & 0.811 & 0.822 & 0.921 & 0.781 \\
\hline 8 & 1.000 & 0.977 & 0.949 & 1.000 & 1.000 & 0.962 & 1.000 & 0.961 & 0.753 & 0.833 & 0.951 & 0.794 \\
\hline 9 & 0.780 & 0.808 & 0.810 & 1.000 & 0.888 & 1.000 & 0.973 & 0.850 & 1.000 & 0.780 & 0.725 & 0.700 \\
\hline 10 & 0.764 & 0.704 & 0.904 & 0.956 & 1.000 & 0.951 & 1.000 & 0.860 & 0.849 & 0.953 & 0.714 & 0.720 \\
\hline 11 & 1.000 & 0.966 & 0.924 & 0.896 & 0.927 & 0.954 & 1.000 & 0.945 & 0.672 & 0.783 & 0.983 & 0.759 \\
\hline 12 & 1.000 & 0.984 & 0.953 & 1.000 & 1.000 & 0.967 & 1.000 & 0.950 & 0.723 & 0.795 & 0.953 & 0.801 \\
\hline $\begin{array}{l}\text { Standard } \\
\text { deviation }\end{array}$ & 0.086 & 0.087 & 0.044 & 0.036 & 0.036 & 0.039 & 0.034 & 0.037 & 0.146 & 0.055 & 0.090 & 0.032 \\
\hline
\end{tabular}

scores of DMUs are reported in the last row. Note that the fluctuation of cross-efficiency scores in the altruism model is the smallest. This indicates that the altruism model can be used to reduce the differences in the cross-efficiency scores of DMUs. Finally, in Table 8, we observe that DMU9 is the worst among all the DMUs. In fact, DMU9 is always ranked the last. Further to the above findings, most of the peer-efficiency scores evaluated by DMU9 are small. This indicates that when peer-efficiency scores of a DMU (when evaluated by other DMUs) are not large, small peer-efficiency scores will be given to the other DMUs.

\section{Conclusions}

Cross-efficiency evaluation is an effective method for assessing efficiency. However, its major drawback is the appearance of non-unique optimal weights. To overcome this deficiency, a secondary goal was incorporated into cross-efficiency evaluation. Thus far, scholars have presented numerous secondary goal models with multiple secondary goals. In this paper, two new secondary goal models were presented to further extend the existing secondary goal models. Specifically, in case the evaluated Decision-Making Unit (DMU) was 
Table 11. Cross-efficiency scores of the exclusiveness model.

\begin{tabular}{|c|c|c|c|c|c|c|c|c|c|c|c|c|}
\hline \multirow{2}{*}{$\begin{array}{l}\text { Rating } \\
\text { DMU }_{d}\end{array}$} & \multicolumn{12}{|c|}{ Rated $\mathrm{DMU}_{j}$} \\
\hline & 1 & 2 & 3 & 4 & 5 & 6 & 7 & 8 & 9 & 10 & 11 & 12 \\
\hline 1 & 1.000 & 0.959 & 0.900 & 0.890 & 0.946 & 0.773 & 0.849 & 0.879 & 0.417 & 0.731 & 0.954 & 0.746 \\
\hline 2 & 0.917 & 1.000 & 0.602 & 0.909 & 0.789 & 0.429 & 0.451 & 0.603 & 0.304 & 0.421 & 0.666 & 0.604 \\
\hline 3 & 1.000 & 0.959 & 0.982 & 0.926 & 1.000 & 0.930 & 0.999 & 0.926 & 0.416 & 0.759 & 0.977 & 0.801 \\
\hline 4 & 0.818 & 0.874 & 0.775 & 1.000 & 0.889 & 0.820 & 0.817 & 0.803 & 0.725 & 0.685 & 0.723 & 0.694 \\
\hline 5 & 0.747 & 0.725 & 0.830 & 0.869 & 1.000 & 0.462 & 0.541 & 0.556 & 0.007 & 0.407 & 0.625 & 0.722 \\
\hline 6 & 0.608 & 0.602 & 0.776 & 0.802 & 0.817 & 1.000 & 0.973 & 0.688 & 0.968 & 0.679 & 0.591 & 0.626 \\
\hline 7 & 0.890 & 0.842 & 0.904 & 0.877 & 0.929 & 0.949 & 1.000 & 0.889 & 0.725 & 0.833 & 0.869 & 0.727 \\
\hline 8 & 1.000 & 0.977 & 0.949 & 1.000 & 1.000 & 0.962 & 1.000 & 0.961 & 0.753 & 0.833 & 0.951 & 0.794 \\
\hline 9 & 0.359 & 0.367 & 0.423 & 0.482 & 0.436 & 0.699 & 0.643 & 0.451 & 1.000 & 0.468 & 0.356 & 0.347 \\
\hline 10 & 0.764 & 0.704 & 0.904 & 0.956 & 1.000 & 0.951 & 1.000 & 0.860 & 0.849 & 0.953 & 0.714 & 0.720 \\
\hline 11 & 1.000 & 0.966 & 0.924 & 0.896 & 0.927 & 0.954 & 1.000 & 0.945 & 0.672 & 0.783 & 0.983 & 0.759 \\
\hline 12 & 1.000 & 0.984 & 0.953 & 1.000 & 1.000 & 0.967 & 1.000 & 0.950 & 0.723 & 0.795 & 0.953 & 0.801 \\
\hline $\begin{array}{l}\text { Standard } \\
\text { deviation }\end{array}$ & 0.199 & 0.196 & 0.165 & 0.140 & 0.162 & 0.199 & 0.202 & 0.175 & 0.290 & 0.175 & 0.199 & 0.126 \\
\hline
\end{tabular}

cooperative with other DMUs, the altruism crossefficiency model was proposed as a means to iteratively maximize the peer-efficiency scores of each DMU. On the other hand, when the evaluated DMU was competing with other DMUs, the exclusiveness crossefficiency model was presented as a means to minimize the peer-efficiency score of each of the other DMUs. The decision-makers could choose their preferred models depending on different application scenarios and requirements. In this paper, two numerical examples were used to illustrate the proposed models. Our results showed that the proposed altruism model (exclusiveness model) had a good ability to maximize (minimize) the peer-efficiency scores of other DMUs.

Our method brings at least three advantages to current cross-efficiency evaluation methods. Firstly, the competition and cooperation game theories are integrated into a Data Envelopment Analysis (DEA) approach, in order to develop two cross-efficiency evaluation models. Compared to cross-efficiency evaluation methods, our proposed models aim to iteratively maximize (or minimize) efficiency ratings of each other DMU, rather than affecting the average overall efficiency of other DMUs. Secondly, although the models presented in this paper were nonlinear, an algorithm was proposed for solving them. We provided two examples in order to verify effectiveness of the proposed algorithm. Finally, in order to solve the non-uniqueness of cross-efficiency scores, we presented and proved the hypothesis of the unique solution for cross efficiency. This proof provided even a greater reason for all DMUs to accept the evaluation results.

This study can be extended in the future. For example, in some real-world applications, the input and output data are stochastic. In this case, our models are not applicable. Some further extensions can consider and address this problem based on stochastic or fuzzy cross-efficiency evaluation methodologies.

\section{Acknowledgement}

This research was supported by Research Project of Philosophy and Social Sciences University of Jiangsu (2016SJD630186) and Industry-University Collaborative Education Project of China's Ministry of Education (No. 201801069100).

\section{References}

1. Charnes, A., Cooper, W.W., and Rhodes, E. "Measuring the efficiency of decision making units", European Journal of Operational Research, 2(6), pp. 429-444 (1978).

2. Chu, J.F., Wu, J., and Song M.L. "An SBM-DEA model with parallel computing design for environmental efficiency evaluation in the big data context: A transportation system application", Annals of Operations Research, 270(1-2), pp. 105-124 (2018).

3. Chu, J., Wu, J., Zhu, Q., An, Q., and Xiong, B. "Analysis of China's regional eco-efficiency: A DEA two-stage network approach with equitable efficiency decomposition", Computational Economics, 54(4), pp. 1263-1285 (2019).

4. Adler, N., Friedman, L., and Sinuany-Stern, Z. "Review of ranking methods in the data envelopment analysis context", European Journal of Operational Research, 140(2), pp. 249-265 (2002).

5. Sexton, T.R., Silkman, R.H., and Hogan, A.J. "Data envelopment analysis: Critique and extensions", 
New Directions for Evaluation, 1986(32), pp. 73-105 (1986).

6. Anderson, T.R., Hollingsworth, K., and Inman, L. "The fixed weighting nature of a cross-evaluation model", Journal of Productivity Analysis, 17(3), pp. 249-255 (2002).

7. Boussofiane, A., Dyson, R.G., and Thanassoulis, E. "Applied data envel- opment analysis", European Journal of Operational Research, 52(1), pp. 1-15 (1991).

8. Shang, J. and Sueyoshi, T. "A unified framework for the selection of a flexible manufacturing system", European Journal of Operational Research, 85(2), pp. 297-315 (1995).

9. Baker, R. and Talluri, S. "A closer look at the use of data envelopment analysis for technology selection", Computers \& Industrial Engineering, 32(1), pp. 101108 (1997).

10. Green, R.H., Doyle, J.R., and Cook, W.D. "Preference voting and project ranking using DEA and cross-evaluation", European Journal of Operational Research, 90(3), pp. 461-472 (1996).

11. Ertay, T. and Ruan, D. "Data envelopment analysis based decision model for optimal operator allocation in CMS", European Journal of Operational Research, 164(3), pp. 800-810 (2005).

12. Wu, J., Liang, L., Zha, Y., and Yang, F. "Determination of cross-efficiency under the principle of rank priority in cross-evaluation", Expert Systems with Applications, 36(3), pp. 4826-4829 (2009).

13. Roboredo, M.C., Aizemberg, L., and Meza, L.A. "The DEA game cross efficiency model applied to the Brazilian football championship", Procedia Computer Science, 55, pp. 758-763 (2015).

14. Doyle, J. and Green, R. "Efficiency and cross-efficiency in DEA: Derivations, meanings and uses", Journal of the Operational Research Society, 45(5), pp. 567-578 (1994).

15. Liang, L., Wu, J., Cook, W.D., and Zhu, J. "Alternative secondary goals in DEA cross-efficiency evaluation", International Journal of Production Economics, 113(2), pp. 1025-1030 (2008).

16. Wang, Y.M., Chin, K.S., and Luo, Y. "Cross-efficiency evaluation based on ideal and anti-ideal decision making units", Expert Systems with Applications, 38(8), pp. 10312-10319 (2011).

17. Lim, S. "Minimax and maximin formulations of crossefficiency in dea", Computers \& Industrial Engineering, 62(3), pp. 726-731 (2012).

18. Wu, J., Chu, J., Sun, J., and Zhu, Q. "Dea crossefficiency evaluation based on Pareto improvement", European Journal of Operational Research, 248(2), pp. 571-579 (2016).
19. Wang, Y.M., Chin, K.S., and Jiang, P. "Weight determination in the cross-efficiency evaluation", Computers \& Industrial Engineering, 61(3), pp. 497-502 (2011).

20. Wu, J., Sun, J., and Liang, L. "Cross efficiency evaluation method based on weight-balanced data envelopment analysis model", Computers \& Industrial Engineering, 63(2), pp. 513-519 (2012).

21. Sun, J., Yang, R., Ji, X., and Wu, J. "Evaluation of decision-making units based on the weight-optimized DEA model", Kybernetika, 53(2), pp. 244-262 (2017).

22. Wu, J., Liang, L., and Zha, Y. "Preference voting and ranking using DEA game cross efficiency model (< special issue $>$ operations research for performance evaluation)", Journal of the Operations Research Society of Japan, 52(2), pp. 105-111 (2009).

23. Song, L. and Liu, F. "An improvement in DEA crossefficiency aggregation based on the Shannon entropy" International Transactions in Operational Research, 25(2), pp. 705-714 (2018).

24. Ruiz, J.L. and Sirvent, I. "Fuzzy cross-efficiency evaluation: a possibility approach", Fuzzy Optimization and Decision Making, 16(1), pp. 111-126 (2017).

25. Chen, H. "Average lexicographic efficiency for data envelopment analysis" Omega, 74(1), pp. 82-91 (2018).

26. Liu, H.H., Song, Y.Y., and Yang, G.L. "Crossefficiency evaluation in data envelopment analysis based on prospect theory", European Journal of Operational Research (2018).

27. Kao, C. and Liu, S.T. "Cross efficiency measurement and decomposition in two basic network systems", Omega (2018).

28. Liang, L., Wu, J., Cook, W.D., and Zhu, J. "The DEA game cross-efficiency model and its Nash equilibrium", Operations Research, 56(5), pp. 1278-1288 (2008).

29. Wu, J., Liang, L., and Chen, Y. "Dea game crossefficiency approach to Olympic rankings", Omega, 37(4), pp. 909-918 (2009).

30. Sun, J., Fu, Y., Ji, X., and Zhong, R.Y. "Allocation of emission permits using dea-game-theoretic model", Operational Research, 17(3), pp. 867-884 (2017).

31. Liu, X., Chu, J., Yin, P., and Sun, J. "Dea crossefficiency evaluation considering undesirable output and ranking priority: a case study of eco-efficiency analysis of coal-fired power plants", Journal of Cleaner Production, 142, pp. 877-885 (2017).

32. Chen, W., Zhou, K., and Yang, S. "Evaluation of china $\varepsilon=$ s electric energy efficiency under environmental constraints: A DEA cross efficiency model based on game relationship", Journal of Cleaner Production, 164, pp. 38-44 (2017).

\section{Biographies}

Lei Li is an Assistant Professor in the School of Business, Applied Technology College of Soochow University. Her research mainly focuses on areas including 
performance evaluation and empirical study. She has published papers in journals such as Expert Systems and Entropy.

Wei Dai is a postgraduate student in the School of Business, Soochow University, China. She obtained a BSc degree from Shanghai Polytechnic University in 2016. Her research interests focus on operations research and decision-making models.

Junfei Chu received his $\mathrm{PhD}$ degree from the University of Science and Technology of China and CentraleSupélec. He is now an Assistant Professor in the School of Business, Central South University. His research interests comprise data envelopment analysis, supply chain management, and dynamic pricing. He has published papers in journals such as European Journal of Operational Research, International Journal of Production Research, Journal of Operational Research Society, and Annals of Operations Research.

Xiaohong Liu is a PhD student at University of Science and Technology of China. Her research interests are data envelopment analysis and environment and energy efficiency analysis. She has published articles in journals including Journal of Cleaner Production, Annals of Operations Research, and Energy Systems.

Yuhong Wang is a Professor in the School of Business, Jiangnan University. Professor Wang's research interests include evidence theory, uncertainty prediction, and decision making method. His articles appear in Expert Systems with Applications, Journal of Systems Engineering and Electronics, Journal of Grey System (UK), and International Journal of Computational Intelligence Systems. 